\title{
Antitrust exemptions for joint R\&D improve patents
}

\author{
Samuli Leppälä1
}

Received: 7 July 2015/Accepted: 21 January 2016/Published online: 18 February 2016

(C) The Author(s) 2016. This article is published with open access at Springerlink.com

\begin{abstract}
Investments in scientific and technological knowledge depend on the level of excludability. In this study, based on a game-theoretic analysis of discrete public goods, it is shown that pure excludability and pure non-excludability are equally inefficient, whereas the socially optimal level of excludability is a function of the benefits and costs of the knowledge investment, where it lies between the two extremes. This result illustrates the challenges and dangers of intellectual property rights policy. Allowing for voluntary R\&D cooperation, the optimal level of excludability becomes an interval, typically between the two extremes. Thus, $R \& D$ cooperation can make intellectual property rights perform more efficiently and alleviate the problem of optimal policy design. This also demonstrates that knowledge commons can be provided efficiently through voluntary cooperation when imperfect property rights give partial excludability. Therefore, R\&D cooperation and intellectual property rights should be considered as complementary rather than as separate and alternative policy measures.
\end{abstract}

Keywords Excludability $\cdot$ Intellectual property rights $\cdot$ Knowledge $\cdot$ Positive externalities $\cdot$ Public goods $\cdot$ R\&D cooperation

JEL Classification $\mathrm{O} 31 \cdot \mathrm{H} 41 \cdot \mathrm{O} 34 \cdot \mathrm{D} 70 \cdot \mathrm{D} 62$

\section{Introduction}

The public good nature of knowledge creates both opportunities and challenges. After its creation, new knowledge can have vast social benefits because of its non-rivalness. However, the extent to which these benefits are gained as well as the incentive required for the initial investment both depend on the level of excludability. There are several known

Samuli Leppälä

leppalasm@cardiff.ac.uk

1 Cardiff Business School, Cardiff University, Colum Drive, Cardiff CF10 3EU, UK 
solutions for providing incentives for innovation, such as intellectual property rights (IPRs), research prizes, R\&D cooperation, and government subsidies, although none of these is without its problems. Using a game-theoretic model of a discrete public good provision, the present study aims to determine the socially optimal level of excludability for purely non-rival knowledge. The main result obtained by the model is that IPR and $\mathrm{R} \& \mathrm{D}$ cooperation should be considered as complementary rather than as alternative policy measures and that efficient provision of knowledge commons can be achieved through the combination of voluntary cooperation and imperfect property rights.

On the backdrop of this article are the past changes in antitrust and IPR policies. Over the course of the 1980s and 1990s, both the USA and Europe became increasingly worried about the Japanese competition, and one of the main policy responses to this was to make antitrust exemptions for R\&D cooperation between firms. For example, the 1984 US National Cooperative Research Act and its amended version in 1993 marked a significant departure from the earlier policy, which was relatively hostile towards any form of interfirm cooperation (Hart 2001). On the other hand, the same two decades saw important reforms in the US patent system, which strengthened patent protection and extended its scope (Gallini 2002). The proposed transcontinental trade agreements of the present day would imply a further step towards global IPR policy, while at the same time the current IPR regimes in the US and elsewhere are facing increasing criticism (e.g., Tabarrok 2002; Shapiro 2008; Boldrin and Levine 2013).

Recently, several studies questioning the need for (strong) IPRs have emerged. For example, Choi (1998) and Krasteva (2014) show that stronger IPRs do not always benefit the innovator. In the former, an intermediate IPR strength drives the innovator to accommodate the first entrant, whereas weaker IPRs lead to a waiting game between potential entrants, which can be more profitable to the innovator. In the latter, $R \& D$ investment is maximized for an intermediate protection level, since some imitation also benefits the innovator in the form of expected damage payments. Furthermore, Bessen and Maskin (2009) show that in the context of sequential innovation the society and even innovators may be better off without IPRs. This outcome arises because, while imitation reduces the profit from current discovery, it raises the probability of subsequent innovations and hence future profits.

The results obtained in this article similarly support imperfect IPRs. In the case of noncooperative investments alone, it turns out that the optimal level is a complex function of the specific costs and benefits even in our stylized model, which suggests that optimal IPR policy alone requires too much knowledge on behalf of the policymakers. Furthermore, it is shown that pure excludability creates an outcome that is equally inefficient as pure nonexcludability. This is due to the duplication of effort induced by the higher monopoly rents of excludable knowledge. Thus, there is a clear danger if policymakers are lobbied for stronger IPR protection.

There is a notable disjoint in the existing literature, however. On the one hand, R\&D cooperation has not been considered in the context of optimal IPRs. On the other hand, while the social benefits of $R \& D$ cooperation have been studied in the industrial organization literature (e.g., d'Aspremont and Jacquemin 1988; Baumol 2001), voluntary participation and the effect of IPRs on these incentives have not been considered there. The game-theoretic public good approach of the current paper brings these aspects together and shows how R\&D cooperation and partial excludability through imperfect IPRs act together to provide optimal innovation incentives.

While Dixit and Olson (2000) demonstrate that the absence of transaction costs alone does not induce much voluntary public good provision, our model shows that a range of 
excludability exists within which voluntary $R \& D$ cooperation can both attract the optimal contributions as well as deter excessive duplication of effort. Recognizing the benefits of and allowing for cooperation decreases the margin for error in IPR policy. Therefore, R\&D cooperation and IPRs should be considered as complementary rather than as separate and alternative policy measures. While favoring the combination of strong IPRs and tough antitrust policies, this policy complementarity has been similarly highlighted by Spulber (2013).

The remainder of this article is organized as follows. Section 2 reviews the underlying problem in knowledge investments and describes the main characteristics of the model. In Sect. 3, we analyze the socially optimal level of excludability in the absence of cooperation. We present the optimal level of excludability as a function of the benefits and costs of $R \& D$ investment as well as showing that the two extremes are equally inefficient in terms of social welfare. In Sect. 4 , we introduce the possibility of R\&D cooperation into the model. The main result demonstrates that the socially optimal level of excludability becomes an interval that again depends on the cost and benefits of the particular knowledge investment in question. It is shown that this complementarity between IPR and R\&D cooperation also holds when there is uncertainty in the outcome of the research project and some degree of duplication is optimal. The last section summarizes our results and discusses their policy implications.

\section{Setup}

Throughout this study, we use the term "knowledge" to refer to scientific and technological knowledge, although the issues discussed also apply to other types of knowledge to various extents. Nevertheless, this type of knowledge most clearly exemplifies the characteristics of a public good, which arguably make the efficient allocation of resources problematic. As such, discussions of the importance of excludability and IPRs have occurred mainly in this context. Before presenting the formal model, this section provides a brief discussion of the reasons for adopting a game-theoretic approach to discrete public goods.

\subsection{Knowledge as a discrete public good}

Instances of pure public goods are hard to find in reality, and many typical examples were later found to be unsatisfactory (Buchanan and Kafoglis 1963; Cheung 1973; Coase 1974). However, knowledge has persisted in this role since Pigou (1920, p. 158), who considered scientific research to be the most important case of positive externalities, subject to underinvestment. Although positive externalities and public goods were originally perceived as different phenomena, in essence both are incentive structures and public goods can be thought of as a special case of externalities (Cornes and Sandler 1996).

Efficient provision of knowledge depends on the level of excludability as various knowledge spillover mechanisms decrease the level of social value that the innovator is able to appropriate. Among others, Arrow (1996, p. 125) noted that: "Patents and copyrights are social innovations designed to create artificial scarcities where none exist naturally. These scarcities are intended to create the needed incentives for acquiring information." However, it has been argued that often some natural excludability of 
knowledge exists, and thus the gap between marginal private and social benefits is not necessarily extensive (e.g., Dosi et al. 2006).

Unlike the perfect non-excludability of knowledge, its perfect non-rivalness, which rarely holds elsewhere, has not been contested. The non-rivalness of knowledge implies that it can be used simultaneously by an infinite number of individuals and in perpetuity without additional costs (Foray 2004, p. 94). However, this non-rivalness led Nelson (1959, p. 305) to acknowledge that the assumption of the homogeneity of knowledge "products" is suspect and thus Pigouvian marginal analysis might not be adequate. In fact, non-rivalness is of great importance because after the good has been produced, there is no need for continuing investment so the costs are fixed (Callon 1994), which implies that knowledge is a discrete public good.

Another important feature that is not captured by the Pigouvian framework is the possibility of strategic interaction. Strategic interaction is particularly important in the case of public goods since non-rivalness implies an opportunity for collective gain, whereas non-excludability implies difficulties in its realization (Ver Eecke 1999). Non-excludability can induce strategic free-riding on the efforts of others, or people may choose to act collectively, particularly when the cost of an action exceeds the individual gain but not their sum. These issues support the use of game-theoretic methods for analyzing knowledge investments (Dasgupta 1988).

\subsection{The model}

We consider a population of $N \geq 2$ players, which are individuals or firms that would benefit from a knowledge investment. The cost of the investment is $C>0$, and the resulting gain (if the investment is successful) is $V$ per player. Constant $V$ implies that knowledge is assumed to have no strategic value by itself in this context. We consider the implications of uncertainty in Sect. 4.2, but, in general, we assume deterministic innovation. Therefore, the gross social gain is $N V$ when one or more investments are made.

We focus on cases where investment is socially feasible such that $N V>C$. A distinction can be made between the cases where the individual gain is less than or more than the investment cost. We refer to the first case, $V \leq C$, as basic scientific research and the second case, $V>C$, as applied scientific research. While the meanings of these terms are different than in The Frascati Manual (OECD 2002), for example, our purpose is to make a distinction between two relevant analytical cases with respect to whether a player might benefit from making the investment if there is no cost sharing or excludability of knowledge. Therefore, this reflects the assumption that underinvestment will be a greater problem for more basic research (Nelson 1959; Arrow 1962).

We assume that there is a patent race, which is a simple winner-takes-all lottery. Thus, all players (or later their coalitions) that invest $C$ have an equal probability of winning the appropriable share of the social benefit $N V$. The level of excludability, $\alpha \in[0,1]$, dictates how the benefits are divided between the patent holder and others. The gain of the individual patent holder will be $V+\alpha(N-1) V$, whereas all others will gain only $(1-\alpha) V$. Therefore, due to the uniform value of $V$ across all $N$ individuals, we assume that the level of excludability is at the same time the level of appropriability. This also implies that there is no monopoly deadweight loss in the model. Although relevant, monopoly deadweight loss is already a well-known issue in the patent literature (Foray 2004; Scotchmer 2004). Instead, we focus on the issue of the efficient investment level because there may be either too little or too much investment. The first problem has been studied widely in the public 
goods literature, while the latter problem is known as duplication of effort in the patent literature (e.g., Loury 1979).

When the level of excludability decreases (increases), part of the social benefit is transferred away from (to) the patent holder. These transfers are neutral from the utilitarian viewpoint, so excludability affects social welfare through the willingness to invest rather than directly. Internalizing social benefits through higher excludability makes the investment more lucrative and decreases the incentive to free-ride on others' efforts, but the problem is that it encourages multiple investments, whereas only one (successful) investment is needed to provide the knowledge. When cooperation becomes an option, the players can also make a joint investment where they share the expected revenue and investment cost equally. If some choose to cooperate, which is not always guaranteed, both free-riding and the duplication of effort decrease.

The characteristics of scientific and technological knowledge strongly support gametheoretic public good analysis, so we consider multiple individuals and their mixed strategies in public good provision. Similar to Palfrey and Rosenthal (1984) and Dixit and Olson (2000), we focus on the mixed strategy equilibrium for two reasons. First, asymmetric pure strategy equilibria arbitrarily require that identical individuals select different strategies. Second, there is a coordination problem when choosing collectively from among the asymmetric equilibria. Thus, the associated uncertainty regarding the final provision will be revealed via mixed strategy equilibria (Dasgupta 1988).

In the spirit of the Coase theorem, we study how the allocation of property rights matters (indirectly) with respect to social welfare. Therefore, to elucidate the implications of excludability, we assume that there are no transaction costs and that the property rights are defined perfectly in the sense that individuals' opportunity sets are defined (Stubblebine 1972). The level of excludability determines how much of the social benefit of knowledge the patent holder is able to appropriate. This appropriation is perfect because of the absence of transaction costs, and the use of the patent system and negotiation with respect to R\&D cooperation are similarly assumed to be costless. In reality, of course, these costs can be non-negligible and shift the balance either way.

In Sect. 3, we study the socially optimal level of excludability when innovation is deterministic and the players can either make or abstain from investment. In Sect. 4, we introduce an additional strategy that allows the players to contribute to a joint investment. In the first subsection, we study the optimal level of excludability when innovation is deterministic, and the second subsection shows how the implications can be extended to the case where there is uncertainty in $\mathrm{R} \& \mathrm{D}$. The respective payoffs of the strategies, $u_{i}$ for each player $i \in N$, are defined in the later sections for convenience. Throughout this study, we use the utilitarian notion of social welfare, which is then given by $U=\sum u_{i}$. Thus, the distribution of costs and benefits only matters for achieving the highest possible social welfare.

\section{Optimal excludability in the absence of cooperation}

In the absence of cooperation, player $i$ can either choose to invest ( $I$ ) or abstain $(A)$. Given deterministic innovation and the level of excludability, $\alpha$, the payoff from the investment is

$$
u_{i}(I)=\frac{\alpha N V}{n}+(1-\alpha) V-C,
$$


where $n \leq N$ is the (expected) number of all investments. The payoff from abstaining is

$$
u_{i}(A)=(1-\alpha) V,
$$

if $n \geq 1$ and zero otherwise. Thus, the net social welfare is

$$
U=N V-n C
$$

if $n \geq 1$ and zero otherwise.

To characterize the resulting equilibria, we use the standard pure strategy Nash equilibrium condition, $x_{i} \in\{I, A\}, x_{i} \neq x_{i}^{*}: u_{i}\left(x_{i}^{*}, x_{-i}^{*}\right) \geq u\left(x_{i}, x_{-i}^{*}\right)$, and the mixed strategy Nash equilibrium condition, $\sigma_{i} \in \mathcal{P}(I, A), \sigma_{i} \neq \sigma_{i}^{*}: u_{i}\left(\sigma_{i}^{*}, \sigma_{-i}^{*}\right) \geq u\left(\sigma_{i}, \sigma_{-i}^{*}\right)$, where $\mathcal{P}$ is the set of probability distributions on the available strategies and the conditions hold for all players $i$.

Let $p \in[0,1]$ be the probability that the players other than $i$ choose $I$ and $1-p$ that they choose $A$. Then, the expected payoff from the investment for player $i$ becomes

$$
u_{i}(I)=\sum_{j=0}^{N-1}\left(\begin{array}{c}
N-1 \\
j
\end{array}\right) p^{j}(1-p)^{N-1-j} \frac{\alpha N V}{j+1}+(1-\alpha) V-C .
$$

When $i$ abstains the probability that $n \geq 1$ is $1-(1-p)^{N-1}$ and the expected payoff from abstaining is

$$
u_{i}(A)=\left(1-(1-p)^{N-1}\right)(1-\alpha) V .
$$

Finally, the net social welfare if all $N$ players choose $I$ with probability $p$ is given by

$$
U=\left(1-(1-p)^{N}\right) N V-p N C .
$$

The policymaker's problem is to maximize net social welfare by choosing the level of excludability such that the players' actions are determined by the mixed strategy equilibrium. In addition to incentive compatibility, the mixed strategy equilibrium also guarantees the individual rationality requirement since by abstaining the players can always achieve a non-negative payoff.

Proposition 1 In the absence of cooperation, the socially optimal level of excludability is given by

$$
\alpha^{*}=\frac{\left(1-\sqrt[N-1]{\frac{C}{N V}}\right)(N-1) C}{N V-C} .
$$

\section{Proof See Appendix 1.}

Proposition 1 demonstrates how the socially optimal level of excludability is conditional on the specific circumstances. Similarly as Tabarrok (2002) and Shapiro (2008), this result strongly suggests that IPR policy should consider the costs and benefits of different knowledge commons. However, the variance in the optimal level of excludability is probably high, and it can be close to pure excludability in some cases while close to pure non-excludability in others. This emphasizes the one-size-fits-all problem of IPRs, i.e., they cannot be tailored for each and every type of knowledge, and thus they are likely to be non-optimal in the vast majority of cases. 
Corollary 1 The socially optimal level of excludability, $\alpha^{*}$, is increasing in $C$, decreasing in $V$, and decreasing in $N$ for $N>\max \left\{N_{0}, N_{1}\right\}$, where $N_{0}$ and $N_{1}$ can be calculated.

\section{Proof See Appendix 1.}

The intuition behind this result is that a higher $C$ or lower $V$ decreases the incentive to invest, and hence a higher level of excludability is required. By contrast, with a higher $N$, each individual becomes less pivotal, which also causes the duplication of effort to become a more severe problem. This latter effect soon becomes dominant, which explains the direction. Although the optimal level of excludability is not always decreasing in $N$, this seems to be generally the case based on our numerical computations.

Corollary 2 Pure excludability, $\alpha=1$, and pure non-excludability, $\alpha=0$, are equally inefficient from the social viewpoint.

\section{Proof See Appendix 1.}

With perfect excludability, the duplicated research effort crowds out all (basic research) or as much as possible (applied research) of the social benefit, which essentially makes the situation a zero-sum game. This result is less surprising if we remind ourselves that it is a general outcome of all-pay auctions, which have been argued to characterize patent races (Dasgupta 1986). The "bid" (i.e., the investment cost) is fixed in this case and the same for everyone, but the use of mixed strategies achieves the same outcome, i.e., the sum of the expected research costs equals the social benefit. This result is also an example of the more general phenomenon of rent dissipation, where the social costs of monopoly not only include the (possible) monopoly deadweight loss, but also the resources used for competing for the monopoly rents (Tullock 1967).

Figure 1 illustrates the situation further and plots the net social welfare, $U$, on the vertical axis against the individual probability of investing, $p$, on the horizontal axis. The optimal probability of investing, $p^{*}$, which is reached by choosing the optimal level of excludability, lies at the top of each curve, the point on the left of the curve denotes the individual probability of investing with pure non-excludability, and the point on the right is the same with pure excludability. As stated by our previous results, the social benefit obtained is equal with pure non-excludability and pure excludability. In the upper row, (a) and (b) show two cases for basic research, and thus the two extremes result in zero social benefit. In the lower row, (c) and (d) show two cases for applied research, where the social benefit is above zero in the case of both extremes, but again significantly lower than what could be achieved with the optimal probability of investing. While the inverted-U relationship between patent strength and innovation has been noted in the literature (Gallini 2002; Tabarrok 2011), Figure 1 reminds us that the same holds between social welfare and $\mathrm{R} \& \mathrm{D}$ expenditures, the latter of which is often used as a measure of innovation.

The downside of excludability, i.e., the duplication of effort, was noted previously by Loury (1979). While it is not surprising that less than perfect IPRs may be socially optimal (Shapiro 2008), it is quite interesting to see that pure excludability yields equally inefficient outcome as pure non-excludability. It is not fully clear what brings this outcome, but it seems to be related to what takes place in homogeneous good oligopolies with R\&D output spillovers (d'Aspremont and Jacquemin 1988; De Bondt et al. 1992). There, it was discovered that the relationship between the firms' effective $R \& D$, which includes own $R \& D$ and spillovers, and the spillover rate has an inverted-U shape and is minimized and equally small with no spillovers and perfect spillovers. Unlike in d'Aspremont and 


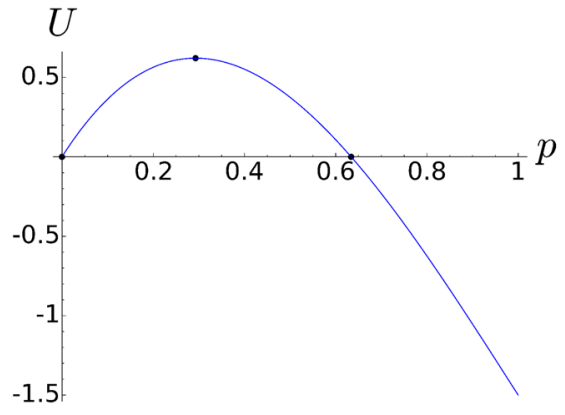

(a) $N=3, V=1, C=1.5, p^{*}=0.2929$

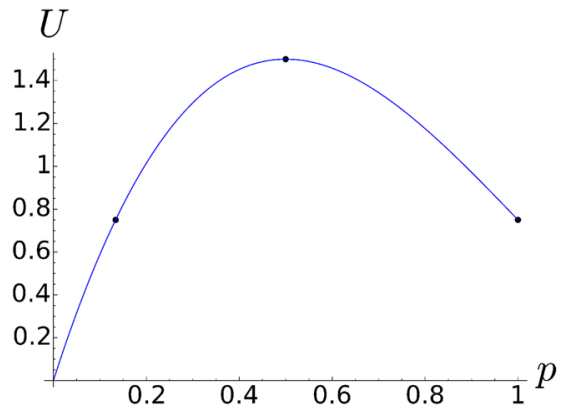

(c) $N=3, V=1, C=0.75, p^{*}=0.5$

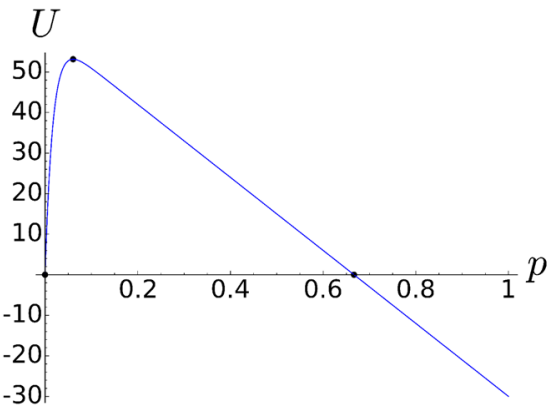

(b) $N=60, V=1, C=1.5, p^{*}=0.0606$

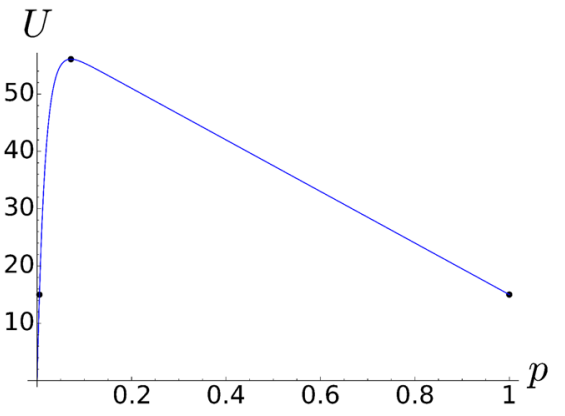

(d) $N=60, V=1, C=0.75, p^{*}=0.0716$

Fig. 1 Net social welfare as a function of the probability of investing

Jacquemin (1988), however, the optimal level of excludability in our model is not fixed (to one half).

To sum up, without R\&D cooperation, the optimal IPR policy would need to be tailored for each separate situation, which is not possible because it requires that the policymaker has perfect knowledge and foresight of all investment opportunities. Furthermore, there is a clear danger when stronger IPR protection is lobbied, e.g., because it would be better to have a small degree of natural excludability rather than perfect excludability through strong IPRs. The logic that strong property rights are always good for the society does not extend to knowledge that is non-rival.

\section{Cooperation and the level of excludability}

As noted by Buchanan (1964), the outcome should not be treated as a market failure simply if no single individual has sufficient incentive to finance the full cost of an essentially indivisible operation because people may or may not decide to act collectively. Similarly, the scholars of the Bloomington School have argued that like other commons, knowledge can be managed cooperatively under the right conditions (Hess and Ostrom 2007). Thus, we now supplement the earlier analysis by assuming that a third strategy, i.e., a joint investment, becomes a possibility.

Various different mechanisms for the private provision of public goods have been proposed (e.g., Bagnoli and Lipman 1992; Tabarrok 1998). In particular, the present study 
most closely follows Dixit and Olson (2000), which is a further development of an earlier model by Palfrey and Rosenthal (1984). In addition to being a discrete public good model, it has two other suitable properties (cf. Bagnoli and Lipman 1989; Saijo and Yamato 1999). First, the mechanism is very simple and realistic compared with many other studies. Second, the individuals have a choice about whether to participate in the mechanism, i.e., it is not imposed upon them, which is crucial when non-excludability is assumed.

In the first stage of Dixit and Olson (2000), all individuals decide simultaneously whether to participate in the provision of the public good. In the second stage, when the number of participants is known, the public good is provided if and only if the private benefit for participants exceeds their equal share of the cost; otherwise, the game ends with no public good provision or cost to anyone. The only possible symmetric pure strategy equilibrium is Pareto optimal, but Dixit and Olson (2000) show that the expected social welfare in the mixed strategy equilibrium becomes very small as the share of the required contributors increases, or the distance between private cost and benefit decreases, which is consistent with the normal assumptions regarding public good provision (Olson 1965). Hence, they argue that the mere lack of transaction costs is not sufficient such that voluntary cooperation would reach the Pareto optimal outcome. In the present study, we show that partial excludability can help to achieve the Pareto optimal outcome. In other words, $R \& D$ cooperation and IPR work in a complementary manner.

If we can make cooperation self-enforcing, we will reach the Pareto optimal outcome where everyone participates in the optimal number of joint R\&D investments. First, this requires that no single player has an incentive to free-ride on the investments of others. Second, no player should have an incentive for trying to acquire the patent through a noncooperative investment. Thus, the socially optimal level of excludability becomes an interval, which is our main result. We consider this situation under deterministic innovation, where the optimal number of investments is one, before we show that the result extends to stochastic innovation, where the optimal number of investments can be greater.

\subsection{Cooperation and deterministic innovation}

Player $i$ can now make the investment $(I)$ or abstain $(A)$ as well as participating in a joint investment $(J)$. Given deterministic innovation and the level of excludability $\alpha$, the payoff from the joint investment is

$$
u_{i}(J)=\frac{\alpha N V}{n m}+(1-\alpha) V-\frac{C}{m},
$$

where $n \leq N$ is the (expected) number of all investments and $m \leq N$ is the (expected) number of players participating in the joint investment. The payoffs obtained from making a non-cooperative investment (1) or abstaining altogether (2) remain the same as before.

In Dixit and Olson (2000), no joint investment is made in the second stage if (7) is negative, and thus the payoff is given by (2). To make the question of voluntary cooperation interesting, we assume that the non-negativity of (7) does not require that everyone participates in the joint investment. In this case, the analysis is also more straightforward than in Dixit and Olson (2000) because we need not consider the probability of the joint investment occurring as we focus on the symmetric equilibrium where it is certain. Thus, in the case of deterministic innovation, the Pareto optimal outcome is that everyone participates in the joint investment with a probability of 1 . We now show that this is an equilibrium outcome for particular levels of excludability. 
Proposition 2 With the possibility of a joint $R \& D$ investment, the socially optimal level of excludability is an interval that depends on the values of $N, V$, and $C$, i.e., $\alpha^{*} \in\left[\frac{C}{N V}, \frac{2 C(N-1)}{N V(N-2)}\right]$.

\section{Proof See Appendix 1.}

Proposition 2 shows that the socially optimal level of excludability is now an interval with upper and lower bounds. The upper bound is not binding in the few cases where it is 1 or greater. Pure excludability and pure non-excludability are generally outside the interval, however, and thus cooperation is not self-enforcing if excludability is either too low or too high.

When R\&D cooperation is possible, i.e., it is not prevented by antitrust law or negotiation costs, this gives more leeway to intellectual property law. With R\&D cooperation, the outcome is improved and designing IPR policies becomes easier with a larger margin for error. From the bounds of the interval, we can observe that they move in the same direction with changes in $C, V$, or $N$, e.g., a higher cost requires higher excludability, but at different speeds. Hence, the length of the interval describes the amount of room for maneuver for the IPR policy.

Corollary 3 The length of the interval for the socially optimal level of excludability, $\left|\alpha^{*}\right|$, is increasing in $C$ and decreasing in $V$ and $N$.

\section{Proof See Appendix 1.}

The intuition behind Corollary 3 is that when $C$ increases, the incentive to compete with a non-cooperative investment $(I)$ decreases more than the incentive to free-ride $(A)$ increases. The opposite holds for an increase in $V$ or $N$ since the incentive to free-ride decreases less than the incentive to make a competing investment increases. In summary, with a high $C$, a higher level of excludability is required but there is also more leeway given the longer interval of optimal excludability, whereas the opposite applies in cases of $V$ and $N$.

Any additional costs or benefits of taking part in the joint investment may of course affect the required excludability. For example, it is straightforward to show that with a large enough transaction cost of cooperation the joint investment may cease to be feasible. However, cooperation may create additional benefits as well that increase the length of the interval for the socially optimal level of excludability. For example, it is a common concern that cooperation between the firms may extend to the product market. While this issue is beyond the scope of the article, there may thus be a further policy tradeoff between IPR-based market power and product market collusion.

\subsection{Cooperation and stochastic innovation}

Hitherto, we have assumed deterministic innovation, where there is no uncertainty in the outcome of the research project. This has facilitated the analysis, because solving for the mixed strategy equilibrium when there is further uncertainty in R\&D output would prove very difficult. In reality, of course, knowledge investments typically involve uncertainty, so we investigate this matter further in this subsection.

Suppose now that an R\&D project is successful with probability $p \in(0,1)$ and that it fails with probability $q=1-p$. In many cases these probabilities also depend on the actions of the players. Hence, we assume that a player or coalition of players $i$ chooses the probability of success $p_{i}$ and pays the R\&D cost $c\left(p_{i}\right)$, where $\lim _{p_{i} \rightarrow 0} c\left(p_{i}\right)>0, c^{\prime}>0$, and 
$c^{\prime \prime}>0$, which imply fixed costs and decreasing returns. (An equivalent approach would be to presume that the probability of success, $p\left(c_{i}\right)$, increases, but at a diminishing rate, with R\&D expenditures $c_{i}$.)

Before proceeding to our main result concerning stochastic innovation, we consider the challenges presented by variable $R \& D$ costs and non-cooperative investment decisions. In this case a simple formation of joint investment projects may not ease the task of IPR policy. Suppose that there are $n$ non-cooperative joint R\&D projects, each of which has $m \leq N / n$ members. Then, coalition $i$ chooses $p_{i}$ to maximise

$$
v_{i}=\alpha N V p_{i} F_{i}+(1-\alpha) m V\left(1-q_{i} \Pi q_{j}\right)-c\left(p_{i}\right),
$$

where $q_{i}=1-p_{i}$ and $i \neq j$. In Eq. (8), $F_{i}$ is $i$ 's probability of winning the patent given its success in the R\&D project, and hence it is a function of other probabilities of success $p_{j}$. More specifically, $F_{i}=\sum_{j=0}^{n-1} \frac{P(s=j)}{j+1}$, where $P(s)$ is the probability that $s$ other coalitions are successful. We assume that the coalitions' members share the costs and benefits equally, and hence the expected net gain of each coalition member, $u_{i}(J)$, is one- $m$ th of (8). For the given $n$, the payoff from abstaining is

$$
u_{i}(A)=(1-\alpha) V\left(1-\Pi q_{j}\right)
$$

If player $i$ opts for private, non-cooperative investment instead, its payoff is given by

$$
u_{i}(I)=\alpha N V p_{i} F_{i}+(1-\alpha) V\left(1-q_{i} \Pi q_{j}\right)-c\left(p_{i}\right) .
$$

Suppose for now that there are only joint investments with $m$ members each and no private investments. Equation (8) gives the following first order condition:

$$
\frac{\partial v_{i}}{\partial p_{i}}=\alpha N V F_{i}+(1-\alpha) m V \Pi q_{j}-c^{\prime}\left(p_{i}\right)=0 .
$$

Since the projects are identical, I assume that the equilibrium is symmetric. Since $p_{i}=p$ for all $i \in n$,

$$
F_{i}=\sum_{j=0}^{n-1}\left(\begin{array}{c}
n-1 \\
j
\end{array}\right) \frac{p^{j} q^{n-1-j}}{1+j}=\frac{1}{p n}\left(1-q^{n}\right) \text { and } \Pi q_{j}=q^{n-1} .
$$

We rewrite (9) as

$$
\frac{\partial v}{\partial p}=\alpha \frac{N V}{p n}\left(1-q^{n}\right)+(1-\alpha) m V q^{n-1}-c^{\prime}(p)=0,
$$

which determines the equilibrium probability of success $p$ given the number of investments $n$.

If all $N$ players are part of a coalition, i.e., $m=N / n$, then (10) becomes

$$
\alpha \frac{N V}{p n}\left(1-q^{n}\right)+(1-\alpha) \frac{N V}{n} q^{n-1}-c^{\prime}(p)=0 .
$$

Whether $n$ is composed of joint or private investments, the expected net social welfare is given by

$$
U=N V\left(1-q^{n}\right)-n c(n) .
$$

As such, the optimal probability of success $p^{*}$ and number of investments $n^{*}$ are given by the first order conditions 


$$
\frac{\partial U}{\partial p}=n N V q^{n-1}-n c^{\prime}(p)=0 \leftrightarrow N V q^{n-1}-c^{\prime}(p)=0
$$

and

$$
\frac{\partial U}{\partial n}=-\ln q N V q^{n}-c(p)=0 .
$$

Consider now the socially optimal R\&D investment given $n$ projects. Substituting (12) into (11) gives us the following proposition:

Proposition 3 Given n non-cooperative joint investments that have m members each, the optimal level of excludability is given by

$$
\alpha=\frac{(n-1)\left(q^{n-1}-q^{n}\right)}{1-q^{n-1}} .
$$

This result indicates that in the presence of uncertainty and variable $R \& D$ costs, it may not be a panacea that players simply form coalitions, because if these coalitions act noncooperatively then the equilibrium $R \& D$ decisions are sensitive to the level of excludability. Hence, achieving the social optimum would require that the policy maker is able to set the correct level of excludability. Furthermore, it is not clear that the same level of excludability would sustain the socially optimal number of joint R\&D projects in the equilibrium as required by the first-best optimum.

The case where the investment efforts are not sensitive to the level excludability or the number of projects arises when there is free entry of private projects. In this case all individual players choose the probability of success that minimizes the average cost. However, as Tandon (1983) shows, this outcome is suboptimal. It can be shown that freeentry of identical joint projects gives the same outcome. This provides an additional reason for including all players into the joint projects in order to prevent excessive entry.

Taking into account the further challenges that stochastic innovation poses, the rest of the article concentrates on two cases under which R\&D cooperation nevertheless achieves the social optimum given an interval of excludability. The first case is very straightforward, since in the case of fixed $R \& D$ costs alone the above-mentioned problem naturally disappears.

Proposition 4 If there are only fixed $R \& D$ costs, then the first-best optimum can be reached with joint investments and a level of excludability that is within an interval given by

$$
\alpha^{*} \in\left[\frac{C n^{*}}{N V\left(1-(1-\rho)^{n^{*}}\right)}, \frac{\left(C\left(N-n^{*}\right)-N V \rho(1-\rho)^{n^{*}}\right)\left(n^{*}+1\right)}{\left(N-n^{*}-1\right) N V\left(1-(1-\rho)^{n^{*}+1}\right)}\right] .
$$

\section{Proof See Appendix 1.}

Proposition 4 shows that as in the case of deterministic innovation, R\&D cooperation and IPRs can be complementary also when there is uncertainty. Note that the upper bound is not binding when $n^{*}=N-1$, i.e., perfect excludability is within the interval if the optimal number of investments is one less than the population size and the risk of duplication is very low. The optimal interval for excludability and optimal number of investments depend on $C, V$, and $N$, so we do not present the comparative statics for the 
length of the interval because of its complexity and cumbersomeness. However, we conjecture that as in the case of stochastic innovation, the length of the interval, and thus the margin for IPR policy, is increasing in $V$ and $N$, and decreasing in $C$.

A further possibility for the first-best optimum comes with a supercoalition. By supercoalition, we mean the situation where, instead of $n$ competing coalitions, these $n$ investment decisions are made cooperatively by a coalition of coalitions, i.e., by a supercoalition. Supercoalition is therefore the strongest form of R\&D cooperation in this framework.

Proposition 5 If forming a supercoaltion is possible, then the first-best optimum can be reached with joint investments and a level of excludability that is within an interval given by

$$
\alpha^{*} \in\left[\frac{c\left(p^{*}\right) n^{*}-\left(q^{\prime n^{*}}-q^{* n^{*}}\right) N V}{N V\left(1-q^{\prime n^{*}}\right)}, \frac{V\left(q_{i} q_{s}^{n}-q^{* n^{*}}\right)-\frac{n^{*} c\left(p^{*}\right)}{N}+c\left(p_{i}\right)}{N V p_{i} \frac{1+q_{s}^{n}}{2}-V\left(1-q_{i} q_{s}^{n}\right)}\right] .
$$

\section{Proof See Appendix 1.}

Proposition 5 shows that also in the case of stochastic innovation a particular interval of excludability is sufficient for the social optimum under R\&D cooperation. While the supercoalition produces the optimal $R \& D$ effort, it requires a specific range of excludability for its stability. This result is also related to other theoretical papers on R\&D cooperation (e.g., Amir 2000), which have found that the stronger the form of cooperation is, the better the outcome from the social point of view. That is, cooperative investment decisions on top of cost sharing can improve the outcome and ease the task of IPR policy.

\section{Conclusion}

In this study, we showed that the socially optimal level of excludability is not the same for all types of knowledge investments, but instead it depends on their costs and benefits. This may help to clarify the controversy regarding the desirability of IPRs and provide support for the claim that the optimal policies for protecting ideas should consider the respective costs and benefits. However, this is a major challenge for intellectual property law because it would place enormously high knowledge requirements on the policymakers. Furthermore, the formidable inefficiency of perfect excludability illustrates the risk when policymakers are lobbied for and biased toward overprotection of ideas.

While the perspective is different from the earlier work in industrial organization, our results similarly demonstrate the welfare improving effect of R\&D cooperation. Although R\&D cooperation used to be as highly suspect by antitrust scholars (Jorde and Teece 1990), important policy changes took place in the US and Europe in the 1980s and 1990s, which led to a substantial increase in R\&D cooperation. In addition to the substantial theoretical justification, the actual outcome has been deemed welfare enhancing as no evidence of subsequent collusion in the product market has been found (Liu et al. 2007). However, it is also the case that the level of cooperation has been low in industries with strong IPRs, such as pharmaceuticals (Vonortas 1997). While thorough empirical research is needed to examine the issue, this outcome is well within the predictions of the model as 
for $R \& D$ cooperation to take place it is necessary that excludability is neither too high nor too low. This suggests that allowing pharmaceutical firms to engage in joint R\&D efforts while simultaneously reducing the strength of patent protection could increase both profits and welfare.

There has been considerable criticism of the current IPR laws during the recent years. At the same, the ideal of strong IPRs has become contested in economic research. The focus has been exclusively on non-cooperative R\&D investments, however, whereas now, especially given the changes in antitrust law, the re-examination of IPR policies should take joint $R \& D$ into account. As shown in this article, $R \& D$ cooperation gives more leeway to intellectual property law as the need to tailor IPRs and the knowledge requirements for the policymakers are reduced. Therefore, antitrust and IPR policies are complements and should be jointly considered. That is, antitrust exemptions for joint R\&D improve patents and, similarly, imperfect patent protection facilitates R\&D cooperation.

Acknowledgments I am grateful for the generous and constructive comments from two anonymous referees. An earlier version of this paper was included in Leppälä, Samuli (2011) Essays in the Economics of Knowledge (Publications of the Turku School of Economics A-8: 2011. Doctoral thesis at the Department of Economics, University of Turku). I would like to thank Suzanne Scotchmer, Tuomas Takalo, Panu Kalmi, Pekka Matomäki, Hannu Vartiainen, Hannu Salonen, and Jenni Jaakkola for their help and suggestions on the previous drafts. The participants at the following seminars and conferences also provided helpful comments: Midwest Economics Association Annual Meetings (Evanston), FDPE Public Economics Workshop (Helsinki), Aboa Centre for Economics Seminar (Turku), FDPE Microeconomics and IO Workshop (Helsinki), and Southern Economic Association Annual Meetings (Atlanta). The usual caveat applies. Lastly, financial support from OP-Pohjola Research Foundation is gratefully acknowledged.

Open Access This article is distributed under the terms of the Creative Commons Attribution 4.0 International License (http://creativecommons.org/licenses/by/4.0/), which permits unrestricted use, distribution, and reproduction in any medium, provided you give appropriate credit to the original author(s) and the source, provide a link to the Creative Commons license, and indicate if changes were made.

\section{Appendix 1}

Proof of Proposition 1 By taking the partial derivative of (6) with respect to $p$, we have

$$
\frac{\partial U}{\partial p}=N^{2} V(1-p)^{N-1}-C N
$$

Since $\partial^{2} U / \partial^{2} p=-(N-1) N^{2} V(1-p)^{N-2}<0$, we find the socially optimal probability to invest by setting (14) as equal to zero, i.e.,

$$
p^{*}=1-\sqrt[N-1]{\frac{C}{N V}}
$$

In the mixed strategy equilibrium, the payoff from investing (4) is equal to the payoff from abstaining (5):

$$
\sum_{j=0}^{N-1}\left(\begin{array}{c}
N-1 \\
j
\end{array}\right) p^{j}(1-p)^{N-1-j} \frac{\alpha N V}{j+1}+(1-\alpha) V-C=\left(1-(1-p)^{N-1}\right)(1-\alpha) V .
$$

After a few simplifying steps, (16) can be rewritten as

$$
\left(1-(1-p)^{N}\right) \alpha V=\left(C-(1-p)^{N-1}(1-\alpha) V\right) p .
$$


Solving (17) for $\alpha$ gives

$$
\alpha=\frac{p\left(C(p-1)+(1-p)^{N} V\right)}{\left(p-1+(1-p)^{N}\right) V} .
$$

The optimal level of excludability should produce the optimal probability to invest. Therefore, we substitute (15) into (18), which yields

$$
\begin{aligned}
\alpha^{*} & =\frac{\left(1-\sqrt[N-1]{\frac{C}{N V}}\right)\left(-\sqrt[N-1]{\frac{C}{N V}} C+V\left(\frac{C}{N V}\right)^{\frac{N}{N-1}}\right)}{-\sqrt[N-1]{\frac{C}{N V}} V+V\left(\frac{C}{N V}\right)^{\frac{N}{N-1}}} \\
& =\frac{\left(1-\sqrt[N-1]{\frac{C}{N V}}\right)(N-1) C}{N V-C}
\end{aligned}
$$

as the optimal level of excludability.

Proof of Corollary 1 The relevant values of $N, V$, and $C$ are given by $N \geq 2, V>0, N V>C>0$. The optimal level of excludability without R\&D cooperation is

$$
\alpha^{*}=\frac{\left(1-\sqrt[N-1]{\frac{C}{N V}}\right)(N-1) C}{N V-C}=\frac{\left(1-\sqrt[N-1]{\frac{C}{N V}}\right)(1-N)}{1-\frac{N V}{C}} .
$$

The partial derivatives are

$$
\begin{aligned}
\frac{\partial \alpha^{*}}{\partial C} & =-\frac{(1-N) N\left(1-\left(\frac{C}{N V}\right)^{\frac{1}{N-1}}\right) V}{C^{2}\left(1-\frac{N V}{C}\right)^{2}}-\frac{(1-N)\left(\frac{C}{N V}\right)^{-1+\frac{1}{N-1}}}{(N-1) N V\left(1-\frac{N V}{C}\right)} \\
& =\frac{(N-1) N V+\left(\frac{C}{N V}\right)^{\frac{1}{N-1}}\left(C-N^{2} V\right)}{(C-N V)^{2}}, \\
\frac{\partial \alpha^{*}}{\partial V} & =\frac{(1-N) N\left(1-\left(\frac{C}{N V}\right)^{\frac{1}{N-1}}\right)}{C\left(1-\frac{N V}{C}\right)^{2}}+\frac{C(1-N)\left(\frac{C}{N V}\right)^{-1+\frac{1}{N-1}}}{(N-1) N V^{2}\left(1-\frac{N V}{C}\right)} \\
& =-\frac{(N-1) N V+\left(\frac{C}{N V}\right)^{\frac{1}{N-1}}\left(C-N^{2} V\right)}{\frac{V}{C}(C-N V)^{2}},
\end{aligned}
$$




$$
\begin{aligned}
\frac{\partial \alpha^{*}}{\partial N}= & \frac{(1-N)\left(1-\left(\frac{C}{N V}\right)^{\frac{1}{N-1}}\right) V}{C\left(1-\frac{N V}{C}\right)^{2}}-\frac{1-\left(\frac{C}{N V}\right)^{\frac{1}{N-1}}}{1-\frac{N V}{C}} \\
& -\frac{(1-N)\left(\frac{C}{N V}\right)^{\frac{1}{N-1}}\left(-\frac{1}{(N-1) N}-\frac{\ln \left[\frac{C}{N V}\right]}{(N-1)^{2}}\right)}{1-\frac{N V}{C}} \\
= & \frac{(N-1) N(V-C)+\left(\frac{C}{N V}\right)^{\frac{1}{N-1}}\left(C(N-1)^{2}+N(N V-C) \ln \left[\frac{C}{N V}\right]\right)}{\frac{1}{C}(N-1) N(C-N V)^{2}} .
\end{aligned}
$$

In (20), the denominator is always positive within the relevant range. We form a new function of the numerator:

$$
f(C)=(N-1) N V+\left(\frac{C}{N V}\right)^{\frac{1}{N-1}}\left(C-N^{2} V\right),
$$

and differentiate it with respect to $C$ to obtain

$$
\begin{aligned}
\frac{\partial f(C)}{\partial C}= & \left(\frac{1}{N V}\right)^{\frac{1}{N-1}} C^{\frac{1}{N-1}-1} \frac{1}{N-1}\left(C-N^{2} V\right)+\left(\frac{C}{N V}\right)^{\frac{1}{N-1}} \\
= & \left(\frac{C}{N V}\right)^{\frac{1}{N-1}}\left(\frac{1}{N-1}\left(1-\frac{N^{2} V}{C}\right)+1\right) \\
& <\left(\frac{C}{N V}\right)^{\frac{1}{N-1}}\left(\frac{1}{N-1}\left(1-\frac{N^{2} V}{N V}\right)+1\right) \\
= & \left(\frac{C}{N V}\right)^{\frac{1}{N-1}}\left(\frac{1}{N-1}(1-N)+1\right)=0 .
\end{aligned}
$$

Therefore, $f^{\prime}(C)<0, \forall C \in(0, N V)$. Furthermore, $f(N V)=(N-1) N V+1 *(N V-$ $\left.N^{2} V\right)=0$. Hence, when $f^{\prime}(C)<0, \forall C \in(0, N V)$, this implies that $f(C)>0, \forall C \in$ $(0, N V)$, and thus $\partial \alpha^{*} / \partial C>0$.

In (21), the denominator is again positive and the numerator is the same as that in (23). We already know that $f(V)>0, \forall V \in(C / N, \infty)$, so we conclude that $\partial \alpha^{*} / \partial V<0$.

The denominator in $(22)$ is positive, and the term, $(C / N V)^{1 /(N-1)}$, in the numerator is increasing in $N$ when

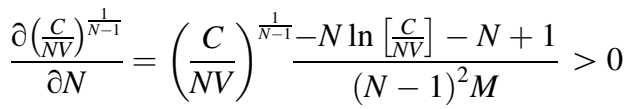

$$
\begin{aligned}
& \leftrightarrow N\left(-\ln \left[\frac{C}{N V}\right]-1\right)+1>0 \leftarrow-\ln \left[\frac{C}{N V}\right]-1>0 \\
& \leftrightarrow \ln \left[\frac{C}{N V}\right]<-1 \leftrightarrow \frac{C}{N V}<e^{-1} \leftrightarrow N>\frac{C e}{V} .
\end{aligned}
$$


Therefore, we know that $(C / N V)^{1 /(N-1)}$ is increasing $\forall N>\max \{C e / V, 2\}$. Thus,

$$
\begin{aligned}
& 1>\left(\frac{C}{N V}\right)^{\frac{1}{N-1}}>\left(\frac{C}{\frac{C e}{V} V}\right)^{\frac{1}{V e}-1}=\left(\frac{1}{e}\right)^{\frac{1}{V e}-1}, \text { when } N>\frac{C e}{V}>2, \text { and } \\
& 1>\left(\frac{C}{N V}\right)^{\frac{1}{N-1}}>\frac{C}{2 V}, \text { when } N>2>1>\frac{C e}{V} .
\end{aligned}
$$

In the following, we use the notation

$$
k=\left(\frac{C}{\max \left\{\frac{C e}{V}, 2\right\} V}\right)^{\frac{1}{\max \left\{\frac{C e, 2}{V},-1\right.}} .
$$

Then, it holds that $1>(C / N V)^{1 /(N-1)}>k$.

Next, we rearrange the numerator in (22) into a polynomial function:

$$
\begin{aligned}
p_{1}(N)= & (N-1) N(V-C)+\left(\frac{C}{N V}\right)^{\frac{1}{N-1}}\left(C(N-1)^{2}+N(N V-C) \ln \left[\frac{C}{N V}\right]\right) \\
= & N^{2}\left(V-C+\left(\frac{C}{N V}\right)^{\frac{1}{N-1}}\left(C+V \ln \left[\frac{C}{N V}\right]\right)\right) \\
& +N\left(C-V+\left(\frac{C}{N V}\right)^{\frac{1}{N-1}}\left(-2 C-C \ln \left[\frac{C}{N V}\right]\right)\right)+\left(\frac{C}{N V}\right)^{\frac{1}{N-1}} C .
\end{aligned}
$$

Inside the first coefficient, $a_{1}$,

$$
C+V \ln \left[\frac{C}{N V}\right]<0 \text { when } N>\frac{e^{\frac{C}{V}} C}{V} .
$$

Therefore,

$$
a_{1}<V-C+k\left(C+V \ln \left[\frac{C}{N V}\right]\right), \text { when } N>\max \left\{\frac{e^{\frac{C}{V}} C}{V}, \frac{C e}{V}, 2\right\} .
$$

Now,

$$
V-C+k\left(C+V \ln \left[\frac{C}{N V}\right]\right)<0, \text { when } N>\frac{C}{V} e^{\frac{C(k-1)+V}{V k}} .
$$

Therefore, $a_{1}<0$ when

$$
N>\max \left\{\frac{C}{V} e^{\frac{C(k-1)+V}{V k}}, \frac{e^{\frac{C}{V}} C}{V}, \frac{C e}{V}, 2\right\} .
$$

Hence,

$$
p_{1}(N)<N^{2}\left(V-C+k\left(C+V \ln \left[\frac{C}{N V}\right]\right)\right)+a_{2} N+\left(\frac{C}{N V}\right)^{\frac{1}{N-1}} C
$$


and

$$
a_{2}<C-V+1 \times\left(-2 C-C \ln \left[\frac{C}{N V}\right]\right), \text { when } N>\frac{e^{2} C}{V},
$$

since

$$
-2 C-C \ln \left[\frac{C}{N V}\right]>0, \text { when } N>\frac{e^{2} C}{V} .
$$

Therefore,

$$
\begin{aligned}
p_{1}(N)< & N^{2}\left(V-C+k\left(C+V \ln \left[\frac{C}{N V}\right]\right)\right) \\
& +\left(C-V+\left(-2 C-C \ln \left[\frac{C}{N V}\right]\right)\right) N+C \\
= & p_{2}(N), \text { when } N>\max \left\{\frac{C}{V} e^{\frac{C(k-1)+V}{V k}}, \frac{e^{\frac{C}{V}} C}{V}, \frac{C e}{V}, 2\right\} .
\end{aligned}
$$

Then,

$$
\begin{aligned}
p_{2}(N)= & \ln \left[\frac{C}{N V}\right]\left(k V N^{2}-C N\right)+N^{2}(C(k+1)+V)+N(-V-C)+C \\
= & \ln \left[\frac{C}{N V}\right]\left(N^{2}(k V-C / N)+N^{2}(C(k+1)+V)+N(-V-C)+C\right. \\
& <\ln \left[\frac{C}{N V}\right]\left(N^{2}(k V-C)+N^{2}(C(k+1)+V)+N(-V-C)+C\right. \\
= & N^{2}\left(C(k-1)+V+(k V-C) \ln \left[\frac{C}{N V}\right]\right)+N(-V-C)+C,
\end{aligned}
$$

where

$$
C(k-1)+V+(k V-C) \ln \left[\frac{C}{N V}\right]<0, \text { when } N>\frac{C}{V} e^{\frac{C-C k-V}{C-k V}} .
$$

We choose

$$
N_{0}=\max \left\{\frac{C}{V} e^{\frac{C-C k-V}{C-k V}}, \frac{C}{V} e^{\frac{C(k-1)+V}{V k}}, \frac{e^{\frac{C}{V}} C}{V}, \frac{C e}{V}, 2\right\}+1 .
$$

Then,

$$
p_{2}(N)<N^{2}\left(C(k-1)+V+(k V-C) \ln \left[\frac{C}{N_{0} V}\right]\right)+N(-V-C)+C=p_{3}(N) .
$$

$p_{3}(N)$ is a degree 2 polynomial, which is zero when either 


$$
\begin{aligned}
N & =\frac{C+V+\sqrt{(-C-V)^{2}-4 C\left(C(-1+k)+V+(-C+k V) \ln \left[\frac{C}{N_{0} V}\right]\right)}}{2\left(C(-1+k)+V+(-V+k V) \ln \left[\frac{C}{N_{0} V}\right]\right)} \\
= & \frac{2 C}{C+V-\sqrt{C^{2}(5-4 k)-2 C V+V^{2}+4 C(C-k V) \ln \left[\frac{C}{N_{0} V}\right]}}=N_{1}
\end{aligned}
$$

or

$$
\begin{gathered}
N=\frac{C+V-\sqrt{(-C-V)^{2}-4 C\left(C(-1+k)+V+(-C+k V) \ln \left[\frac{C}{N_{0} V}\right]\right)}}{2\left(C(-1+k)+V+(-V+k V) \ln \left[\frac{C}{N_{0} V}\right]\right)} \\
=\frac{2 C}{C+V+\sqrt{C^{2}(5-4 k)-2 C V+V^{2}+4 C(C-k V) \ln \left[\frac{C}{N_{0} V}\right]}}=N_{2} .
\end{gathered}
$$

Since (24) is greater than (25), we conclude that $p_{3}(N)<0, \forall N>N_{1}$. In summary: $p_{1}(N)<p_{3}(N)<0, \forall N>\max \left\{N_{0}, N_{1}\right\}$, and thus $\partial \alpha^{*} / \partial N<0, \forall N>\max \left\{N_{0}, N_{1}\right\}$.

Proof of Corollary 2 When $\alpha=1$, the equation for the mixed strategy equilibrium (16) becomes

$$
\sum_{j=0}^{N-1}\left(\begin{array}{c}
N-1 \\
j
\end{array}\right) p^{j}(1-p)^{N-1-j} \frac{N V}{j+1}-C=0
$$

which can be further simplified to

$$
1-(1-p)^{N}=p \frac{C}{V}
$$

Note that if $V>C$, Eq. (26) cannot hold for $p \in[0,1]$ since the LHS will be larger. Therefore, if $V>C$, every player invests with probability $p=1$ and the social welfare (6) becomes

$$
U_{1}=N(V-C) .
$$

If $C \geq V$, then Eq. (26) holds. Substituting (26) into (6) gives

$$
U_{2}=p \frac{C}{V} N V-p N C=0 .
$$

When $\alpha=0$, the equation for the mixed strategy equilibrium (16) becomes

$$
V-C=\left(1-(1-p)^{N-1}\right) V
$$

Note that if $C>V$, Eq. (26) cannot hold for $p \in[0,1]$ since the RHS will be larger. Therefore, if $C>V$, every player invests with probability $p=0$. In addition, no investments are made when $V=C$. Therefore, the social welfare (6) when $C \geq V$ is $U_{2}^{\prime}=0=$ $U_{2}$. If $V>C$, then Eq. (27) holds. Solving (27) for $p$ gives 


$$
p=1-\sqrt[N-1]{\frac{C}{V}}
$$

Substituting (28) into (6) gives

$$
\begin{aligned}
U_{1}^{\prime} & =\left(1-\left(1-\left(1-\sqrt[N-1]{\frac{C}{V}}\right)\right)^{N}\right) N V-\left(1-\sqrt[N-1]{\frac{C}{V}}\right) N C \\
& =N\left(V-V\left(\frac{C}{V}\right)^{\frac{N}{N-1}}-C+C\left(\frac{C}{V}\right)^{\frac{1}{N-1}}\right) \\
& =N(V-C)=U_{1},
\end{aligned}
$$

and hence the social welfare is always the same in the two extreme cases.

Proof of Proposition 2 To ensure a single joint investment with probability 1, the level of excludability should be sufficiently high such that no single player wishes to deviate and abstain from the investment. With $n=1$ and $m=N$, this holds when

$$
u_{i}(J)=V-\frac{C}{N} \geq V(1-\alpha)=u_{i}(A)
$$

or

$$
\alpha \geq \frac{C}{N V} .
$$

The level of excludability should not be too high in order to ensure that no single player has the incentive to deviate for a non-cooperative investment. With $n=1$ and $m=N$, this holds when

$$
u_{i}(J)=V-\frac{C}{N} \geq \frac{\alpha N V}{2}-C+V(1-\alpha)=u_{i}(I)
$$

or

$$
\alpha \leq \frac{2 C(N-1)}{N V(N-2)}
$$

Combining these two conditions gives us an interval for the socially optimal level of excludability, which is

$$
\alpha \in\left[\frac{C}{N V}, \frac{2 C(N-1)}{N V(N-2)}\right]
$$

and this completes the proof.

Proof of Corollary 3 The length of the interval is given by

$$
\left|\alpha^{*}\right|=\frac{2 C(N-1)}{N V(N-2)}-\frac{C}{N V}=\frac{C}{V(N-2)},
$$

based on which it is easy to see that $\partial\left|\alpha^{*}\right| / \partial C>0, \partial\left|\alpha^{*}\right| / \partial V, \partial\left|\alpha^{*}\right| / \partial N<0$. 
Proof of Proposition 4 If the R\&D costs are fixed such that $c(p)=C$, then each project also succeeds with an exogenously given probability $p_{i}=\rho$ for all $i \in n$. This implies that the social optimum depends only on the number of investments. That is, rewriting (13) as

$$
-\ln (1-\rho)(1-\rho)^{n} N V-C=0
$$

yields

$$
n^{*}=\frac{\ln \left(\frac{-C}{N V \ln (1-\rho)}\right)}{\ln (1-\rho)}
$$

as the socially optimal number of investments. To ensure exactly $n^{*}$ joint investments, the level of excludability should be sufficiently high such that no single player wishes to deviate and abstain from the investment:

$$
u_{i}(J)=\left(1-(1-\rho)^{n^{*}}\right) V-\frac{n^{*} C}{N} \geq\left(1-(1-\rho)^{n^{*}}\right)(1-\alpha) V=u_{i}(A)
$$

or

$$
\alpha \geq \frac{C n^{*}}{N V\left(1-(1-\rho)^{n^{*}}\right)} .
$$

The level of excludability should also not be excessively high in order to ensure that no single player has the incentive to deviate for a non-cooperative investment:

$$
\begin{aligned}
u_{i}(J) & =\left(1-(1-\rho)^{n^{*}}\right) V-\frac{n^{*} C}{N} \\
& \geq \alpha \frac{N V}{n^{*}+1}\left(1-(1-\rho)^{n^{*}+1}\right)-C+(1-\alpha) V\left(1-(1-\rho)^{n^{*}+1}\right)=u_{i}(I)
\end{aligned}
$$

or

$$
\alpha \leq \frac{\left(C\left(N-n^{*}\right)-N V \rho(1-\rho)^{n^{*}}\right)\left(n^{*}+1\right)}{\left(N-n^{*}-1\right) N V\left(1-(1-\rho)^{n^{*}+1}\right)} .
$$

Combining these two conditions gives us an interval for the socially optimal level of excludability, i.e.,

$$
\alpha^{*} \in\left[\frac{C n^{*}}{N V\left(1-(1-\rho)^{n^{*}}\right)}, \frac{\left(C\left(N-n^{*}\right)-N V \rho(1-\rho)^{n^{*}}\right)\left(n^{*}+1\right)}{\left(N-n^{*}-1\right) N V\left(1-(1-\rho)^{n^{*}+1}\right)}\right]
$$

and this completes the proof.

Proof of Proposition 5 If everyone participates in the supercoalition, then the coalition's $\mathrm{R} \& \mathrm{D}$ decision is given by (12) since $v_{s}=U$. Then using (13), the policy maker can set a rate of appropriability that yields the first-best optimal number of investments $n^{*}$ as well as $\mathrm{R} \& \mathrm{D}$ intensities $p^{*}$.

If player $i$ abstains, then the supercoalition chooses $p^{\prime}$ to maximize

$$
v_{s}=(N-1+\alpha) V\left(1-q^{n}\right)-n c(n) .
$$

The first order condition, 


$$
\frac{\partial v_{s}}{\partial p^{\prime}}=n(N-1+\alpha) V q^{\prime n-1}-n c^{\prime}\left(p^{\prime}\right)=0,
$$

yields the equilibrium probability of success $p^{\prime}\left(=1-q^{\prime}\right)$.

An individual coalition member has no incentive to deviate and abstain from the supercoalition if

$$
u_{i}(J)=\left(1-q^{* n^{*}}\right) V-\frac{n^{*} c\left(p^{*}\right)}{N} \geq\left(1-q^{\prime n^{*}}\right)(1-\alpha) V=u_{i}(A)
$$

or

$$
\alpha \geq \frac{c\left(p^{*}\right) n^{*}-\left(q^{n^{*}}-q^{* n^{*}}\right) N V}{N V\left(1-q^{\prime n^{*}}\right)},
$$

where $p^{\prime}\left(q^{\prime}\right)$ is given by (29).

If player $i$ competes against the supercoalition it chooses $p_{i}$ in order to maximize

$$
u_{i}=\alpha N V p_{i} \frac{1+q_{s}^{n}}{2}+(1-\alpha) V\left(1-q_{i} q_{s}^{n}\right)-c\left(p_{i}\right),
$$

whereas the supercoalition with $n$ projects chooses $p_{s}$ in order to maximize

$$
v_{s}=\alpha N V\left(1-q_{s}^{n}\right) \frac{1+q_{i}}{2}+(1-\alpha)(N-1) V\left(1-q_{i} q_{s}^{n}\right)-n c\left(p_{s}\right) .
$$

Note that the above assumes that only the overall probability of success, not the number of successful $R \& D$ projects, matters for winning the patent. The first order conditions,

$$
\frac{\partial u_{i}}{\partial p_{i}}=\alpha N V \frac{1+q_{s}^{n}}{2}+(1-\alpha) V q_{s}^{n}-c^{\prime}\left(p_{i}\right)=0
$$

and

$$
\frac{\partial v_{s}}{\partial p_{s}}=\alpha n N V q_{s}^{n-1} \frac{1+q_{i}}{2}+(1-\alpha) n(N-1) V q_{i} q_{s}^{n-1}-n c^{\prime}\left(p_{s}\right)=0,
$$

together yield the equilibrium probabilities of success $p_{i}\left(=1-q_{i}\right)$ for the individual player and $p_{s}\left(=1-q_{s}\right)$ for the supercoalition in this event.

Therefore, no single player has the incentive to deviate for a non-cooperative investment if

$$
\begin{aligned}
u_{i}(J) & =\left(1-q^{* n^{*}}\right) V-\frac{n^{*} c\left(p^{*}\right)}{N} \\
& \geq \alpha N V p_{i} \frac{1+q_{s}^{n}}{2}+(1-\alpha) V\left(1-q_{i} q_{s}^{n}\right)-c\left(p_{i}\right)=u_{i}(I)
\end{aligned}
$$

or

$$
\alpha \leq \frac{V\left(q_{i} q_{s}^{n}-q^{* n^{*}}\right)-\frac{n^{*} c\left(p^{*}\right)}{N}+c\left(p_{i}\right)}{N V p_{i} \frac{1+q_{s}^{n}}{2}-V\left(1-q_{i} q_{s}^{n}\right)}
$$

where $p_{i}\left(q_{i}\right)$ and $p_{s}\left(q_{s}\right)$ are given by (30) and (31). Combining these two conditions gives us an interval for the socially optimal level of excludability, i.e., 


$$
\alpha^{*} \in\left[\frac{c\left(p^{*}\right) n^{*}-\left(q^{\prime n^{*}}-q^{* n^{*}}\right) N V}{N V\left(1-q^{\prime n^{*}}\right)}, \frac{V\left(q_{i} q_{s}^{n}-q^{* n^{*}}\right)-\frac{n^{*} c\left(p^{*}\right)}{N}+c\left(p_{i}\right)}{N V p_{i} \frac{1+q_{s}^{n}}{2}-V\left(1-q_{i} q_{s}^{n}\right)}\right]
$$

and this completes the proof.

\section{References}

Amir, R. (2000). Modelling imperfectly appropriable R\&D via spillovers. International Journal of Industrial Organization, 18(7), 1013-1032.

Arrow, K. (1962). Economic welfare and the allocation of resources for invention. In R. R. Nelson (Ed.), The rate and direction of inventive activity: economic and social factors. Princeton: Princeton University Press.

Arrow, K. J. (1996). The economics of information: An exposition. Empirica, 23(2), 119-128.

Bagnoli, M., \& Lipman, B. L. (1989). Provision of public goods: Fully implementing the core through private contributions. Review of Economic Studies, 56(4), 583-601.

Bagnoli, M., \& Lipman, B. L. (1992). Private provision of public goods can be efficient. Public Choice, 74(1), 59-78.

Baumol, W. J. (2001). When is inter-firm coordination beneficial? The case of innovation. International Journal of Industrial Organization, 19(5), 727-737.

Bessen, J., \& Maskin, E. (2009). Sequential innovation, patents, and imitation. RAND Journal of Economics, 40(4), 611-635.

Boldrin, M., \& Levine, D. K. (2013). The case against patents. Journal of Economic Perspectives, 27(1), $3-22$.

Buchanan, J. M. (1964). What should economists do? Southern Economic Journal, 30(3), 213-222.

Buchanan, J. M., \& Kafoglis, M. Z. (1963). A note on public goods supply. American Economic Review, 53(3), 403-414.

Callon, M. (1994). Is science a public good? Fifth Mullins Lecture, Virginia Polytechnic Institute, 23 March 1993. Science, Technology \& Human Values, 19(4), 395-424.

Cheung, S. N. (1973). The fable of the bees: An economic investigation. Journal of Law and Economics, 16(1), 11-33.

Choi, J. P. (1998). Patent litigation as an information-transmission mechanism. American Economic Review, $88(5), 1249-63$.

Coase, R. H. (1974). The lighthouse in economics. Journal of Law and Economics, 17(2), 357-376.

Cornes, R., \& Sandler, T. (1996). The theory of externalities, public goods, and club goods. Cambridge: Cambridge University Press.

Dasgupta, P. (1986). The theory of technological competition. In J. Stiglitz \& G. Mathewson (Eds.), New developments in the analysis of market structure (pp. 519-547). Houndmills: Macmillan.

Dasgupta, P. (1988). Patents, priority and imitation or, the economics of races and waiting games. Economic Journal, 98(389), 66-80.

d'Aspremont, C., \& Jacquemin, A. (1988). Cooperative and noncooperative R\&D in duopoly with spillovers. American Economic Review, 78(5), 1133-1137.

De Bondt, R., Slaets, P., \& Cassiman, B. (1992). The degree of spillovers and the number of rivals for maximum effective R\&D. International Journal of Industrial Organization, 10(1), 35-54.

Dixit, A., \& Olson, M. (2000). Does voluntary participation undermine the Coase Theorem? Journal of Public Economics, 76(3), 309-335.

Dosi, G., Malerba, F., Ramello, G. B., \& Silva, F. (2006). Information, appropriability, and the generation of innovative knowledge four decades after Arrow and Nelson: An introduction. Industrial and Corporate Change, 15(6), 891-901.

Foray, D. (2004). Economics of knowledge. Cambridge, MA: MIT Press.

Gallini, N. T. (2002). The economics of patents: Lessons from recent US patent reform. Journal of Economic Perspectives, 16(2), 131-154.

Hart, D. M. (2001). Antitrust and technological innovation in the US: Ideas, institutions, decisions, and impacts, 1890-2000. Research Policy, 30(6), 923-936.

Hess, C., \& Ostrom, E. (Eds.). (2007). Understanding knowledge as a commons: From theory to practice. Cambridge: MIT Press.

Jorde, T. M., \& Teece, D. J. (1990). Innovation and cooperation: Implications for competition and antitrust. Journal of Economic Perspectives, 4(3), 75-96. 
Krasteva, S. (2014). Imperfect patent protection and innovation. Journal of Industrial Economics, 62(4), $682-708$.

Liu, Y., O'Reilly-Allen, M., \& Zantout, Z. (2007). The welfare effects of the National Cooperative Research Act (NCRA) of 1984 and the National Cooperative Production Amendments (NCPA) of 1993. American Journal of Economics and Sociology, 66(5), 985-1004.

Loury, G. C. (1979). Market structure and innovation. Quarterly Journal of Economics, 93(3), 395-410.

Nelson, R. R. (1959). The simple economics of basic scientific research. Journal of Political Economy, 67(3), 297-306.

OECD (2002). Frascati manual: Proposed standard practice for surveys on research and experimental development. Paris: Organization for Economic Co-operation and Development.

Olson, M. (1965). The logic of collective action: Public goods and the theory of groups. Cambridge, MA: Harvard University Press.

Palfrey, T. R., \& Rosenthal, H. (1984). Participation and the provision of discrete public goods: A strategic analysis. Journal of Public Economics, 24(2), 171-193.

Pigou, A. C. (1920). The economics of welfare. London: Macmillan.

Saijo, T., \& Yamato, T. (1999). A voluntary participation game with a non-excludable public good. Journal of Economic Theory, 84(2), 227-242.

Scotchmer, S. (2004). Innovation and incentives. Cambridge, MA: MIT Press.

Shapiro, C. (2008). Patent reform: Aligning reward and contribution. In A. B. Jaffe, J. Lerner, \& S. Stern (Eds.), Innovation policy and the economy (pp. 111-156). Chicago: University of Chicago Press.

Spulber, D. (2013). How do competitive pressures affect incentives to innovate when there is a market for inventions? Journal of Political Economy, 121(6), 1007-1054.

Stubblebine, W. C. (1972). On property rights and institutions. In G. Tullock (Ed.), Explorations in the theory of anarchy (pp. 39-50). Blacksburg, VA: The Public Choice Society.

Tabarrok, A. (1998). The private provision of public goods via dominant assurance contracts. Public Choice, 96(3-4), 345-362.

Tabarrok, A. (2002). Patent theory versus patent law. Contributions to Economic Analysis \& Policy, 1(1), $1-26$.

Tabarrok, A. (2011). Launching the innovation renaissance: A new path to bring smart ideas to market fast. New York: TED Books.

Tandon, P. (1983). Rivalry and the excessive allocation of resources to research. Bell Journal of Economics, 14(1), 152-165.

Tullock, G. (1967). The welfare costs of tariffs, monopolies, and theft. Economic Inquiry, 5(3), $224-232$.

Ver Eecke, W. (1999). Public goods: An ideal concept. Journal of Socio-Economics, 28(2), 139-156.

Vonortas, N. S. (1997). Research joint ventures in the US. Research Policy, 26(4), 577-595. 